\section{The influence of iris color and pupil size on expressed affect}

\author{
QUANA R. JONES and ISAIAH S. MOYEL \\ Columbus College, Columbus, Ga. 31907
}

An $8 \times 10$ in. black-and-white photograph of an adult male stranger was presented to each of four randomly assigned groups of male college students. These photographs were identical except that in two of them the stranger had light-colored irises and, in the other two, dark-colored ones. Also, in the light-iris set, one print had large pupils and the other small. Similarly, in the dark-colored set, one print had large pupils and the other small. A total of six sets of four prints each were presented and the students were required to express either positive or negative affect for the photographic subjects. The results revealed a significant relationship between iris color and expressed affect. A nonsignificant effect was obtained for pupil size and for the iris color and pupil size interaction.

In a recent investigation of the effectiveness of instruction at Columbus College, 861 undergraduate students were asked to list some specific instructor behaviors they perceived as undesirable in the classroom.

The lists submitted included complaints that the instructor looked out the window, looked at the floor, or looked at the ceiling too much and, frequently, that he failed to look at the students enough.

In view of the results of recent pupillometric studies (Kahneman \& Beatty, 1966; Hess \& Polt, 1964, 1966; Simms, 1967), which suggest that significant relationships obtain between mental activity, attitudes, affect, sex, and pupil size, it appeared that student resentment of these kinds of instructor behaviors might be attributable to a kind of information deprivation to which these behaviors were subjecting them.

Further, since iris-pupil albedo ratios are higher for light-colored irises than for dark-colored ones, it seemed that the magnitude of deprivation might vary as a function of iris color. That is, the size of an instructor's pupils would be more easily discerned, and thus provide more of the hypothesized information, if his irises were light in color.

The purpose of this investigation was to ascertain whether college students would differ in expressed affect for strangers whose photographs differed only in eye color and in pupil size, and the following hypotheses were tested: (1) There will be no difference in expressed affect for strangers whose photographs differ in iris color. (2) There will be no difference in expressed affect for strangers whose photographs differ in pupil size. (3) There will be no difference in expressed affect for strangers as a function of the iris color and pupil size interaction.

\section{SUBJECTS}

Ss included 59 male undergraduate students enrolled in a course in introductory psychology at Columbus College. Their ages ranged from 18 to 46 years with a mean age of 21.8 years. All Ss were volunteers and were naive regarding the nature of the experiment.

\section{APPARATUS}

Ten sets of four prints each were obtained of black and white $8 \times 10 \mathrm{in}$. photographs of six male and four female local residents whose ages ranged from 18 to 45 years and who consented to the use of their photographs in a psychological experiment.

The prints of a given set were identical with the following exceptions. Each set consisted of two subsets of two prints each. In one subset, the photographic subjects appeared to have light-colored irises, and, in the other, they appeared to have dark-colored ones. Within each subset, the photographic subject in one print appeared to have large pupils, and, in the other, he appeared to have small ones.

Since these effects were obtained through the use of photographic "touch-up" artistry, it was considered necessary to subject all photographs to a validation study. Subsequently, each set was presented to 34 Columbus College students, each of whom was asked to sort the prints into the appropriate categories, i.e., light color, large pupil; light color, small pupil; dark color, large pupil; dark color, small pupil.

Those sets whose prints were sorted correctly by 31 or more of the 34 "judges" were used in the experiment and the adoption of this criterion resulted in the loss of the four sets of photographs in which the photographic subjects were female. Consequently, in order to minimize sexual bias, only males were used as experimental Ss.
DESIGN

A I by 2 factorial experiment in a random-groups design was used. One treatment consistad of stimulus comparisons in which irises of the photographic subjects were light in color and the other featured comparisons in which iris colors were dark. The two levels of each treatment were established on the basis of whether the size of the photugraphic subject's pupil was large or small.

Thus, Ss in the four treatment groups were presented photographs in which the photographic subjects had light-colored irises/large pupils. light-colored irises/small pupils, dark-colored irises/large pupils, and dark-colored. irises/small pupils, respectively.

Ss were randomly assigned to the treatment groups and each $S$ was presented the six photographs which comprised his assigned treatment in random order. For example, each $S$ assigned to the first treatment group was presented six photographs in each of which the photographic'subject had light-colored irises and large pupils. Each $\mathrm{S}$ assigned to the second treatment group was presented six photographs in each of which the photographic subject had light-colored irises and small pupils, and so on.

Twenty Ss were originally assigned to each treatment group. However, after elimination of those $S s$ who recognized one or more of the photographic subjects. there remained $15 \mathrm{Ss}$ in the light-iris/large-pupil treatment, $13 \mathrm{Ss}$ in the light-iris/small-pupil treatment. 12 Ss in the dark-iris/large-pupil treatment, and $19 \mathrm{Ss}$ in the dark-iris/small-pupil treatment, for a total of $59 \mathrm{Ss}$.

All photographs were presented at 15 -sec intervals, and each $S$ was permitted to view each photograph for approximately $60 \mathrm{sec}$, after which he was asked to express either positive (friendly) or negative (not friendly) feelings of affect toward the photographic subject. The total number of positive responses were compiled for each treatment group, and these data were subjected to an analysis of variance.

\section{PROCEDURE}

Upon entering the experimental room, each $S$ was presented a check sheet which requested him to examine carefully each of the pictures that were presented to him and, if he felt that he could easily become friendly with the photographic subject, to check the box labeled FRIENDLY. If he felt that it would be difficult for him to become friendly with that person, he was requested to check the box labeled NOT FRIENDLY. He was also requested to notify the $E$ if he recognized any of the persons in the photographs. 
Table 1

Number of Positive (Friendly) Responses

\begin{tabular}{lcccc} 
& & \multicolumn{3}{c}{ Treatment Leveis } \\
\cline { 2 - 5 } & A 1B 1 & A B 2 & A 2B 1 & A2B 2 \\
\hline Sums & 65 & 58 & 43 & 72 \\
Heans & 4.33 & 4.46 & 3.58 & 3.79 \\
$N$ & 15 & 13 & 12 & 19 \\
\hline
\end{tabular}

Vote-A $i=$ light iris, $A 2=$ dark iris, $B I=$ large pupil. $B 2=$ small pupil.

After the instructions were read, E presented at random the six pictures, which comprised the S's assigned set, to the $S$ in a one-at-a-time order. The $S$ was permitted to look at the picture for as long as $60 \mathrm{sec}$, if needed, after which he was presented the next picture. Approximately $15 \mathrm{sec}$ elapsed between presentations. After the $S$ had rated all of the pictures in his set. he was thanked and dismissed.

RESULTS AND DISCUSSION

Positive (friendly) responses were recorded for each $S$ during his respective six trials and the sums of these responses by treatment are presented in Table 1. Also shown are treatment means and the number of Ss in each treatment.

An effect of the attrition which resulted from recognition of photographic subjects by experimental Ss was to yield cell frequencies which were not only unequal but also disproportionate. Accordingly, the method of unweighted means (Myers, 1966) was used to analyze the data presented in Table 1.

The significant main effect of iris color $(F=5.68, \mathrm{df}=1 / 55, \mathrm{p}<.05)$ permits the rejection of the first hypothesis, which states that expressed affect will not differ as a function of iris color. The nonsignificant main effect of pupil size and the nonsignificant interactive effect of iris color and pupil size require that the second and third hypotheses be accepted

Interestingly, as shown in Table 1 , the mean number of positive affect statements was significantly greater for photographic subjects whose irises were light in color than for those whose irises were dark. This finding is, of course, in the predicted direction, and possibly is due to the increased information provided by such eyes. The failure of pupil-size differences to elicit differential affective responses is more difficult to explain.

Hess (1965) presented to a group of 20 men two pictures of an attractive young woman which were identical except that in one picture the young woman's pupils were extra large and in the other they were very small. The mean affective response to the picture with the large pupils was twice as large as that to the one with the small pupils. Presumably. what is appealing about large pupils in a woman is that they imply positive affect for the man at whom she is looking.

It seems likely that this appeal and concomitant positive affect would be lessened if the sex of the person in the photograph was the same as that of the $S$, as was the case in the present investigation. Indeed, support for this assumption has been provided by Hess, Seltzer, \& Shlien (1965) who found a significant difference between pupil response of heterosexual and homosexual males when viewing pictures of males and females. Additional support is provided by Simms (1967) whose Ss revealed less affect (less pupil dilation) when viewing photographs of persons of their own sex than when viewing photographs of members of the opposite sex. In his discussion of these results, Simms posed the question of whether the pupillary response pattern would also be reflected in the stated interest of Ss.

Since the results of the present study as shown in Table 1 reveal less affect (less stated interest) by $S$ s in exactly the same order as obtained by Simms, they relate directly to his question. It also appears noteworthy that these effects were obtained regardless of the color of the irises of photographic subjects.

Finally, it should be noted that the Ss in Hess's study had an opportunity to compare identical prints in which pupil size varied. whereas no such opportunity was provided for $S s$ in the present investigation.

In summary, the results of this study reveal that the iris-pupil albedo ratios of adult human males, as inferred from black-and-white photographs, exert a significant influence on the way in which they are perceived by male college students.

Since the age range of these photographic subjects was not significantly different from that encountered among male college faculty members, it appears that a similar perceptual bias may be induced by some male faculty members in their male students.

These findings require support from additional studies which assess the relative influence of this variable when the "photographic subject-observer" conditions feature sex interaction.

\section{REFERENCES}

HESS, E. H. Attitude and pupil size. Scientific American, 1965, 212, 46-54.

HESS, E. H., \& POLT, J. M. Pupil size in relation to mental activity during simple problem solving. Science, 1964, 143, 1190-1192.

HESS, E. H., \& POLT, J. M. Changes in pupil size as a measure of taste differences. Perceptual \& Motor Skills, 1966, 23, 451-455.

HESS, E. H., SELTZER, A. L., \& SHLIEN, J. M. Pupil response of hetero- and homosexual males to pictures of men and women: A pilot study. Journal of Abnormal Psychology, 1965, $70,165-168$

KAHNEMAN, D., \& BEATTY, J. Pupil diameter and load on memory. Science, 1966. 154, 1583-1885.

MYERS, J. L. Fundamentals of experimental design. Boston: Allyn \& Bacon, 1966 Pp. 104-108.

SIMMS, T. Pupillary response of male and female subjects to pupillary difference in male and female picture stimuli. Perception \& Psychophysics, 1967, 2, 553-555.

\title{
Further evidence for linguistic operations in the analysis of class-membership statements*
}

\author{
WILLIAM J. KROSSNER \\ Fordham University, Bronx, N.Y. 10458
}

Ss comparing various pairs of linguistically unlike statements to ascertain their logical status-same or contrary-conformed in their behavior to a model which predicts the utilization of two operations to perform the task.

In a previous article (Krossner, 1970), it was shown that Ss analyzing pairs of logically equivalent but linguistically differing class-membership statements of the sort, "All cats are mammals; no cats are

\footnotetext{
*Project done while the author was a postdoctoral fellow at the Harvard University Center for Cognitive Studies and supported by various grants to that agency.
}

nonmammals," utilize two types of operations. The operations transform a class-membership statement into any of its logical equivalents. Times to solution and error likelihoods in the experimental task were shown to depend monotonically on the number of operations that would be required to convert one member of a given pair of statements into the other. 